\title{
The urinary excretion and tissue retention of cyanocobalamin by subjects given repeated parenteral doses
}

\author{
J. F. ADAMS \\ From the Western Infirmary, Glasgow
}

SYNOPSIS The urinary excretion of injected cyanocobalamin was studied in 30 previously untreated vitamin $B_{12}$-deficient patients by measuring the urinary radioactivity after repeated injections of ${ }^{58} \mathrm{Co}$ vitamin $\mathrm{B}_{12}$. The dose range used was 54 to $30,000 \mu \mathrm{g}$., each patient receiving the same dose at each injection.

The results show that there is no constant trend to the excretion of greater or smaller proportions of the amount injected. It is also shown that there is a wide variation in the amounts excreted by each individual and between individual patients and that the capacity of the tissues to retain injected cyanocobalamin is very great, the amounts retained often being greatly in excess of the normal body stores. The excretion of radioactivity after parenteral infections of ${ }^{58} \mathrm{Co}$ vitamin $\mathrm{B}_{12}$ was usually complete within 24 hours but exceptions to this were seen.

The significance and value of the results is discussed.

It is well established that a proportion of an injection of cyanocobalamin (vitamin $\mathbf{B}_{12}$ ) is excreted in the urine in the subsequent 24 to 48 hours. One might expect, particularly in the case of patients with Addisonian pernicious anaemia, that with repeated injections of cyanocobalamin, the amount excreted in urine would increase pari passu with the increase in body stores, possibly reaching a stage at which the tissues were saturated when virtually all the injected dose would be excreted.

Relatively little work has been done on this subject but there appears to be general agreement that the proportion of a parenteral dose of cyanocobalamin which is excreted in the urine increases as the body stores are augmented by repeated injections. Observations made in the course of other studies suggested that it might be of interest to reinvestigate this problem using more accurate techniques than those employed previously. This was done in a large series of patients and the results are presented in this paper.

PATIENTS, MATERIALS, AND METHODS

Observations were made on 30 patients, each of whom was given repeated injections of the same dose of cyanocobalamin. Before treatment all patients had a

Received for publication 21 March 1963. macrocytic anaemia, megaloblastic erythropoiesis seen on marrow biopsy smears, and a low serum vitamin $\mathbf{B}_{12}$ level $(<80 \mu \mu \mathrm{g} . / \mathrm{ml}$. determined by the method of Hutner, Bach, and Ross, 1956). The final diagnosis in each case was based on these findings and on additional evidence, from augmented histamine test meals (Kay, 1953), faecal fat estimations, xylose absorption tests, radioactive vitamin $B_{12}$ absorption tests with and without intrinsic factor, using the method of Schilling (1953) and of Adams and Seaton (1961), and gastric biopsy and intestinal biopsy according to the nature of the case, these tests being performed during or after the studies reported here.

The proportion of each injection of cyanocobalamin excreted was measured by giving only ${ }^{58} \mathrm{Co}$ vitamin $\mathrm{B}_{12}$ and measuring the radioactivity excreted in urine. Urine was collected in acid-washed dark glass bottles for 24 hours before the first injection of ${ }^{58} \mathrm{Co}$ vitamin $\mathbf{B}_{12}$ and for at least 24 hours after each injection. In most cases uninterrupted 24-hour collections were made for the whole of the observation period which extended for at least 24 hours after the last injection. The majority of patients received injections at intervals of one to three days; in some cases the injections were given at intervals ranging from one to five weeks. No haematinic therapy, other than ${ }^{58} \mathrm{Co}$ vitamin $\mathrm{B}_{12}$, was given during the observation period.

In some cases the effect of drugs or differing routes of administration on the urinary excretion of injected ${ }^{58} \mathrm{Co}$ vitamin $\mathbf{B}_{12}$ was also studied. These measures, which will be the subject of a separate report, were without 
significant effect on the amounts of ${ }^{58} \mathrm{Co}$ vitamin $\mathbf{B}_{12}$ excreted and it is therefore valid to include these results in this series.

${ }^{58}$ Co vitamin $B_{12}$ was obtained from the Radiochemical Centre, Amersham, and stock solutions of $0.5 \mu \mathrm{g} .0 .5 \mu \mathrm{c}$. in $5 \mathrm{ml}$. saline were prepared and stored in dark glass bottles at $+4{ }^{\circ} \mathrm{C}$. when not in use. Solutions of ${ }^{58} \mathrm{Co}$ vitamin $\mathbf{B}_{12}$ for injection were prepared by adding the appropriate amount of commercially available cyanocobalamin to the appropriate volume of stock solution of ${ }^{58} \mathrm{Co}$ vitamin $\mathrm{B}_{12}$. The doses used ranged from $54 \mu \mathrm{g}$. $0.3 \mu \mathrm{c}$. to $30,000 \mu \mathrm{g}$. $0 \cdot 1 \mu \mathrm{c}$. The same batch of ${ }^{58} \mathrm{Co}$ vitamin $B_{12}$ was used for each patient. The cyanocobalamin content of the stock solutions were assayed microbiologically each week in order to detect deterioration.

The radioactivity in the urine collections was measured by counting the radioactivity in $450 \mathrm{ml}$. aliquots as described by Adams and Seaton (1961) and the total radioactivity in each collection was expressed as a percentage of the radioactivity in a single injected dose.

\section{RESULTS}

The diagnosis in each case is given in Table I. All patients had a complete haematological response as shown by a rise in the reticulocyte count and the restoration of peripheral blood values to normal.

Radioactivity was not detected in any collection of urine obtained before treatment. Deterioration of the stock solutions of ${ }^{58} \mathrm{Co}$ vitamin $\mathrm{B}_{12}$ in viti was not observed on serial microbiological assays:

The amounts of radioactivity excreted are mos conveniently presented in diagrammatic form Figures 1 to 30 . The total amount of ${ }^{58} \mathrm{Co}$ vitami $\mathbf{B}_{12}$, expressed in micrograms, given to each patien the total amount excreted, and the total amourif retained, as calculated from these two values, is shown in Table $I$. The mean value of radioactivit 9 excreted, expressed as a percentage of a single dosẹ and the standard deviation are shown in Table II

\section{DISCUSSION}

In all previous investigations of this nature the urinary loss of injected cyanocobalamin has been measured by microbiological assay techniques which have an error of about $\pm 20 \%$ (Ross Hutner, and Bach, 1957; Killander, 1957, 1958, Shinton, 1959; Girdwood, 1960), an error whics may be considerably magnified by the necessar use of dilutions of urine of up to 1 in 1,000 or ever more depending on the concentration of cyanocobalamin. The method used in this study is un questionably superior, the only significant source of error being in the isotope counting when it was no greater than $\pm 2 \%$ in the vast majority of results The radioactivity in urine after parenteral injection

TABLE I

DETAILS OF PATIENTS AND TOTAL AMOUNTS OF ${ }^{58} \mathrm{CO}$ VITAMIN B $_{12}$ INJECTED AND EXCRETED AND CALCULATED

\begin{tabular}{|c|c|c|c|c|c|c|}
\hline & & & & RETAINED & & \\
\hline $\begin{array}{l}\text { Case } \\
\text { No. }\end{array}$ & Sex & $\begin{array}{l}\text { Age } \\
\text { (yr.) }\end{array}$ & Diagnosis & $\begin{array}{l}{ }^{68} \mathrm{Co} B_{12} \\
\text { Injections }(\mu \mathrm{g} .)\end{array}$ & $\begin{array}{l}\text { Total }{ }^{58} \mathrm{Co} B_{12} \\
\text { Injected }(\mu \mathrm{g} .)\end{array}$ & $\begin{array}{c}\text { Total }{ }^{58} \text { Co } B_{12} \\
\text { Excreted }(\mu \mathrm{g} .)\end{array}$ \\
\hline
\end{tabular}

\begin{tabular}{rlll}
\hline 1 & M & 48 & Malabsorber \\
2 & M & 40 & Pernicious anaemia \\
3 & M & 58 & Post-gastrectomy megaloblastic anaemia \\
4 & F & 80 & Malabsorber \\
5 & F & 72 & Pernicious anaemia \\
6 & F & 55 & Pernicious anaemia \\
7 & F & 47 & Pernicious anaemia \\
8 & M & 77 & Pernicious anaemia \\
9 & F & 65 & Pernicious anaemia \\
10 & M & 40 & Pernicious anaemia \\
11 & M & 60 & Pernicious anaemia \\
12 & F & 47 & Malabsorber, dietary deficiency \\
13 & M & 59 & Pernicious anaemia \\
14 & M & 59 & Pernicious anaemia \\
15 & F & 51 & Pernicious anaemia \\
16 & F & 48 & Pernicious anaemia \\
17 & M & 54 & Pernicious anaemia \\
18 & F & 70 & Pernicious anaemia \\
19 & F & 51 & Pernicious anaemia \\
20 & F & 62 & Pernicious anaemia \\
21 & M & 55 & Loop syndrome \\
22 & F & 66 & Pernicious anaemia \\
23 & F & 51 & Post-gastrectomy megaloblastic anaemia \\
24 & M & 45 & Post-gastrectomy megaloblastic anaemia \\
25 & M & 67 & Pernicious anaemia \\
26 & F & 63 & Pernicious anaemia \\
27 & F & 69 & Pernicious anaemia \\
28 & M & 52 & Pernicious anaemia \\
29 & M & 70 & Pernicious anaemia \\
30 & M & 65 & Dietary deficiency \\
& & & \\
& & & \\
\hline
\end{tabular}

$\begin{aligned} 10 & \times 54 \\ 10 & \times 54 \\ 10 & \times 54 \\ 8 & \times 100 \\ 9 & \times 100 \\ 16 & \times 100 \\ 17 & \times 100 \\ 17 & \times 100 \\ 18 & \times 100 \\ 15 & \times 540 \\ 18 & \times 540 \\ 8 & \times 1,000 \\ 12 & \times 1,000 \\ 12 & \times 1,000 \\ 12 & \times 1,000 \\ 12 & \times 1,000 \\ 14 & \times 1,000 \\ 16 & \times 1,000 \\ 18 & \times 1,000 \\ 14 & \times 1,140 \\ 16 & \times 1,140 \\ 6 & \times 5,000 \\ 10 & \times 5,000 \\ 10 & \times 5,000 \\ 12 & \times 5,000 \\ 14 & \times 10,000 \\ 15 & \times 10,000 \\ 18 & \times 10,000 \\ 17 & \times 20,000 \\ 6 & \times 30,000\end{aligned}$

540
540
540
800
900
1,600
1,700
1,700
1,800
8,100
9,720
8,000
12,000
12,000
12,000
12,000
12,000
16,000
18,000
12,960
18,240
30,000
50,000
50,000
60,000
140,000
150,000
180,000
340,000
180,000

74
139
46
215
449
874
910
515
758
5,808
6,989
5,728
7,896
8,868
6,240
7,884
9,282
11,956
12,402
7,279
12,513
24,240
42,875
40,500
51,540
89,180
106,500
173,520
256,700
138,240

Calculated Tot ${ }^{58} \mathrm{Co} \mathrm{B}_{12}$ Retained ( $\mu$ g.) 


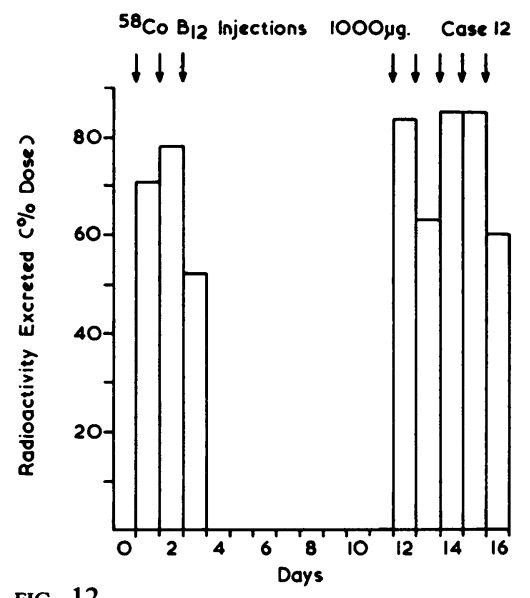

FIG. 12

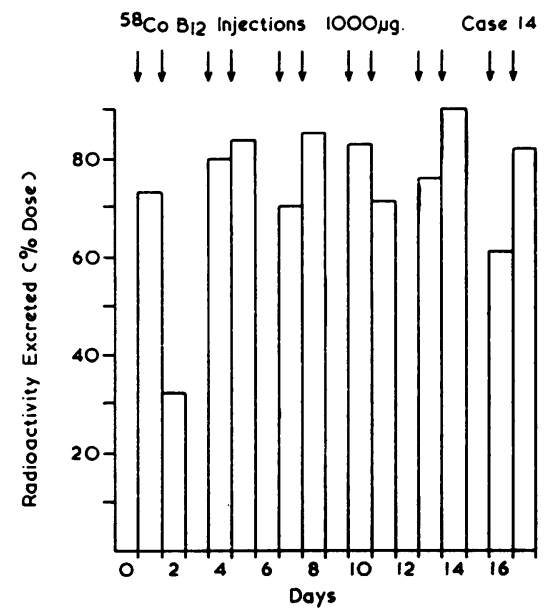

FIG. 14
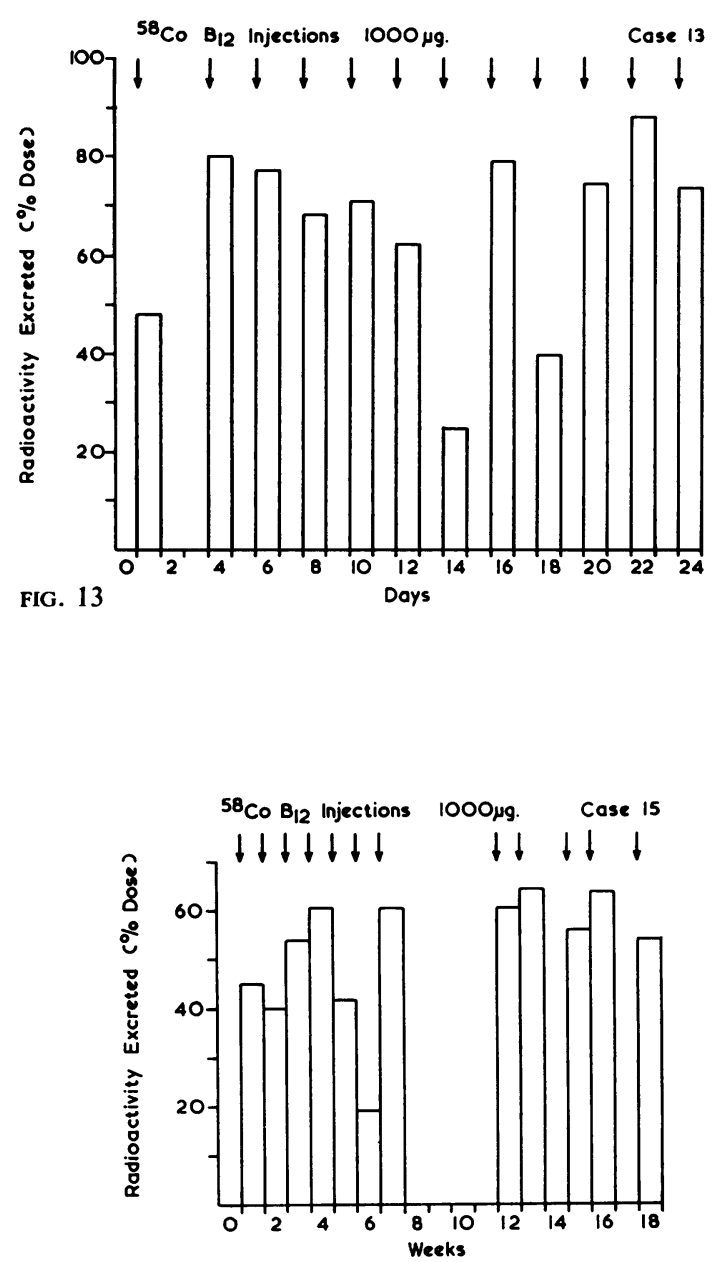

FIG. 15

${ }^{58} \mathrm{Co}_{12}$ Injections $1000 \mu \mathrm{g}$ Case 16 $\downarrow \downarrow \downarrow \downarrow 1 \downarrow \downarrow \downarrow \downarrow \downarrow \downarrow \downarrow$
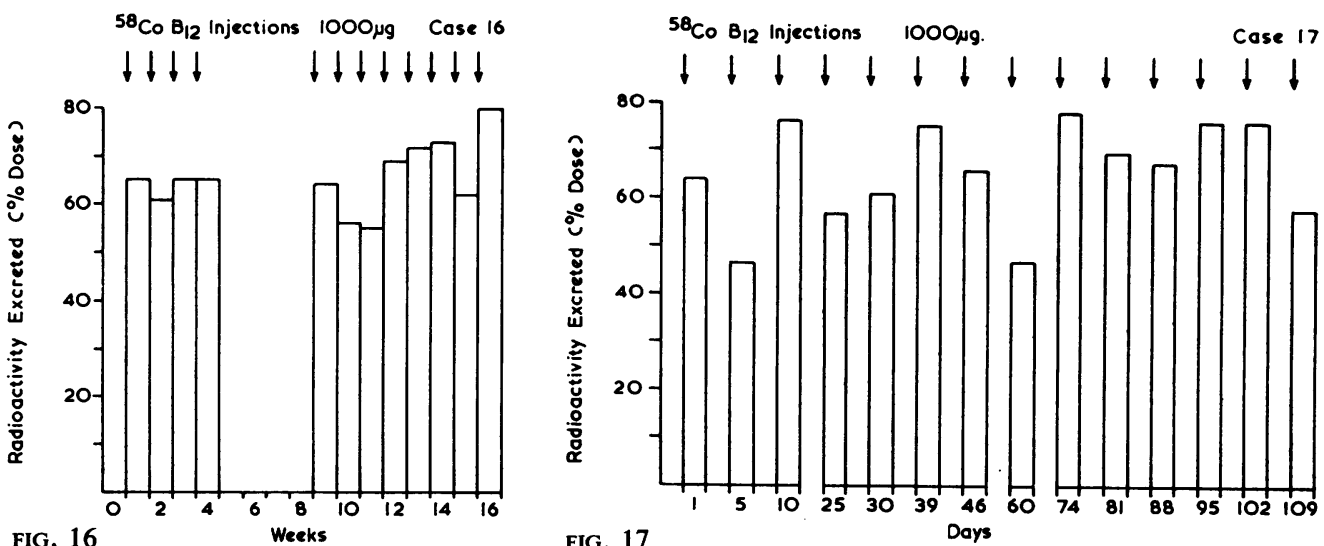

금

N

N

స్ట

뭉

음

$\stackrel{\mathbb{D}}{\mathscr{9}}$

뭉

용

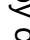

을 

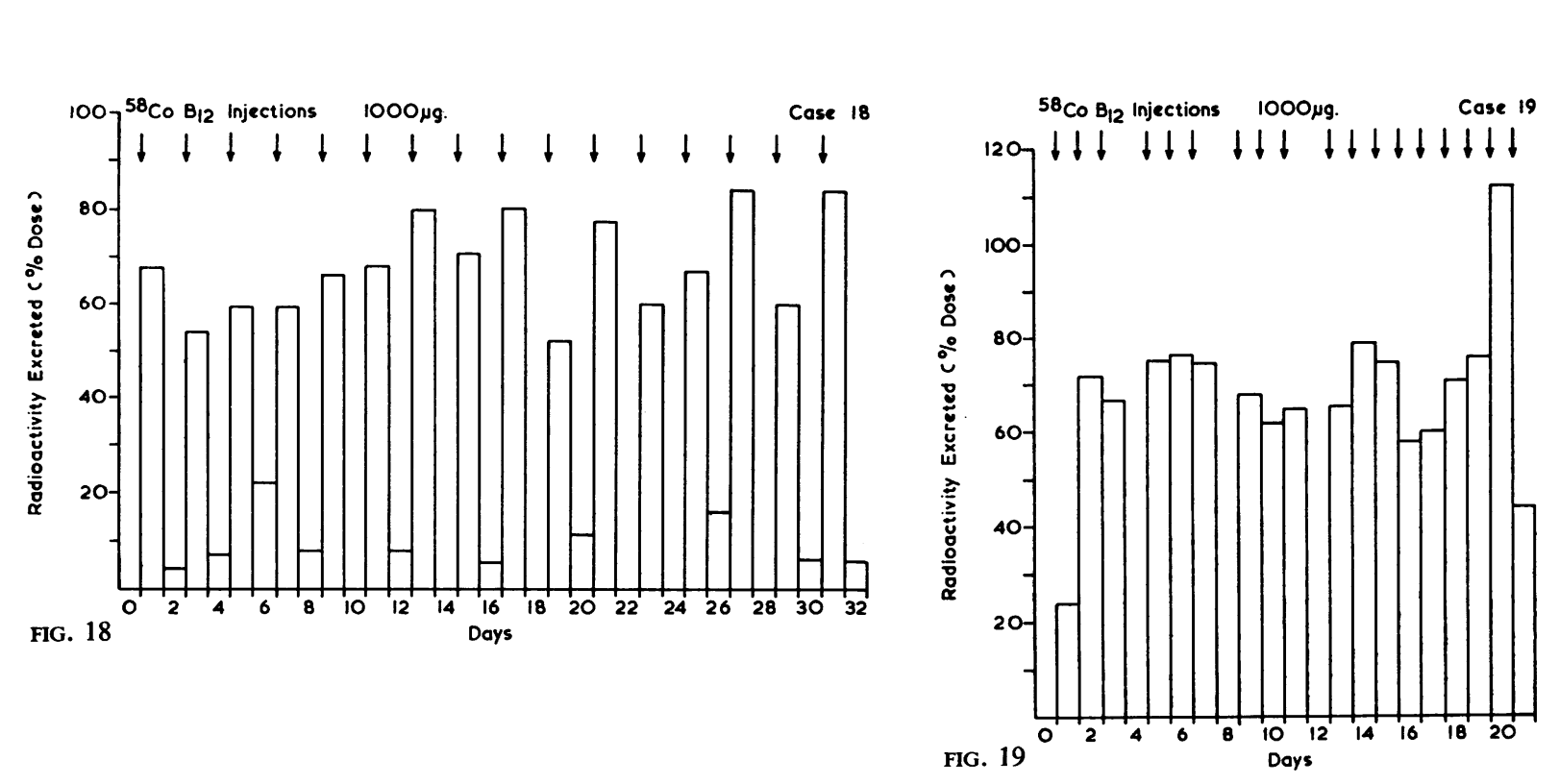

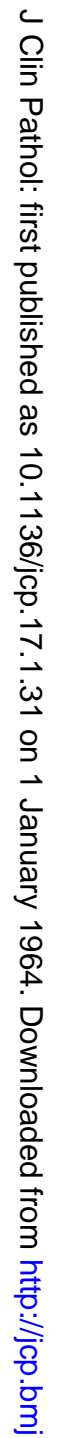

FIG. 21

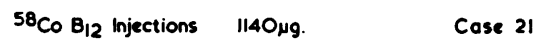

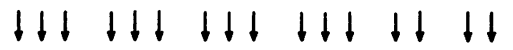
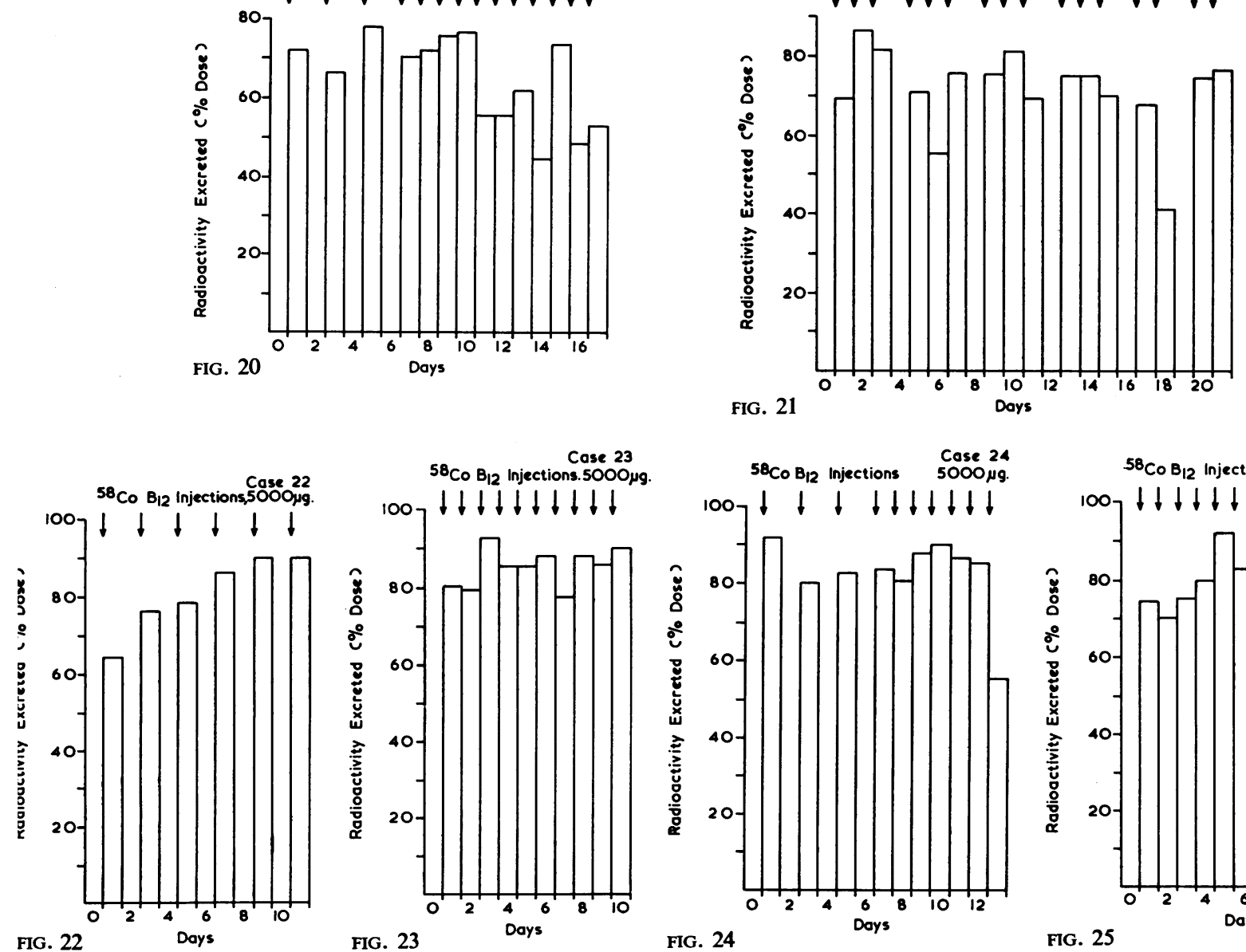

58 Co $B_{12}$ Injections $\begin{array}{r}\text { Cose } 24 \\ 5000 \mu g .\end{array}$

${ }^{58} \mathrm{COB}_{12}$ Injections $\begin{gathered}\text { Cose } \\ 5000\end{gathered}$

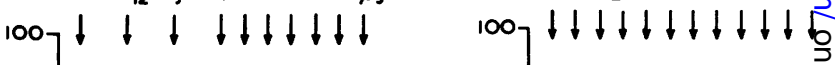
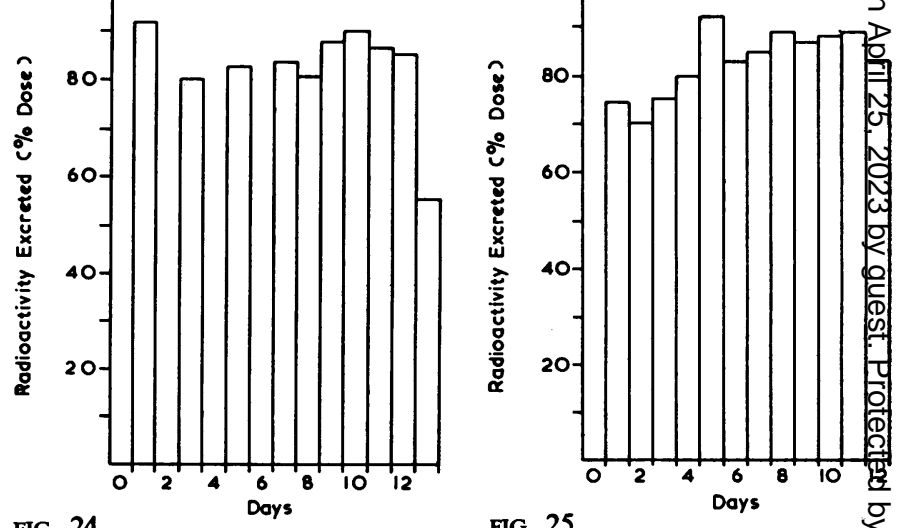

FIG. 25 


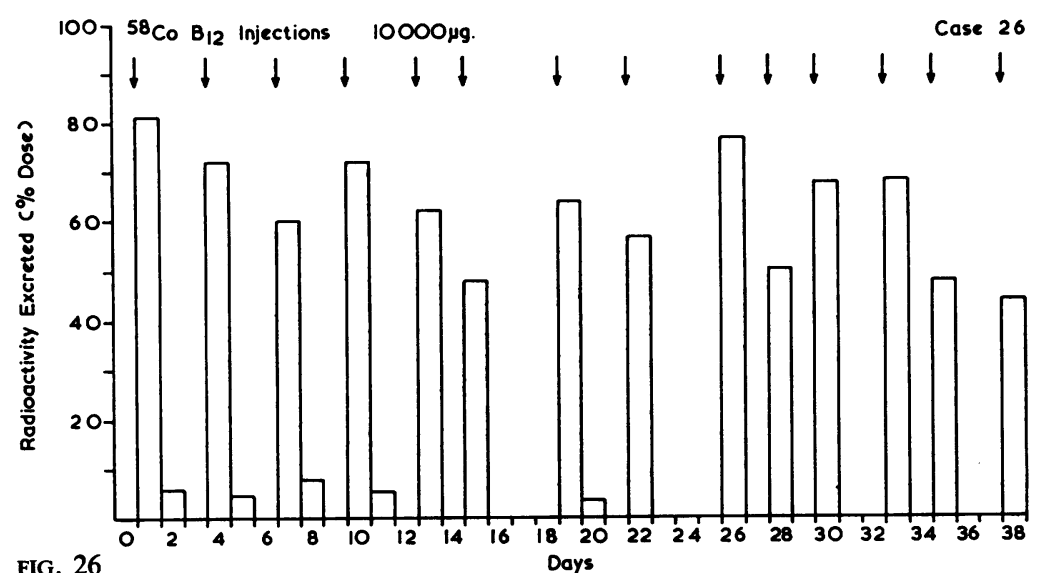

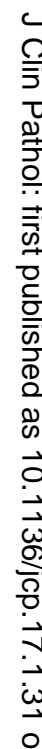
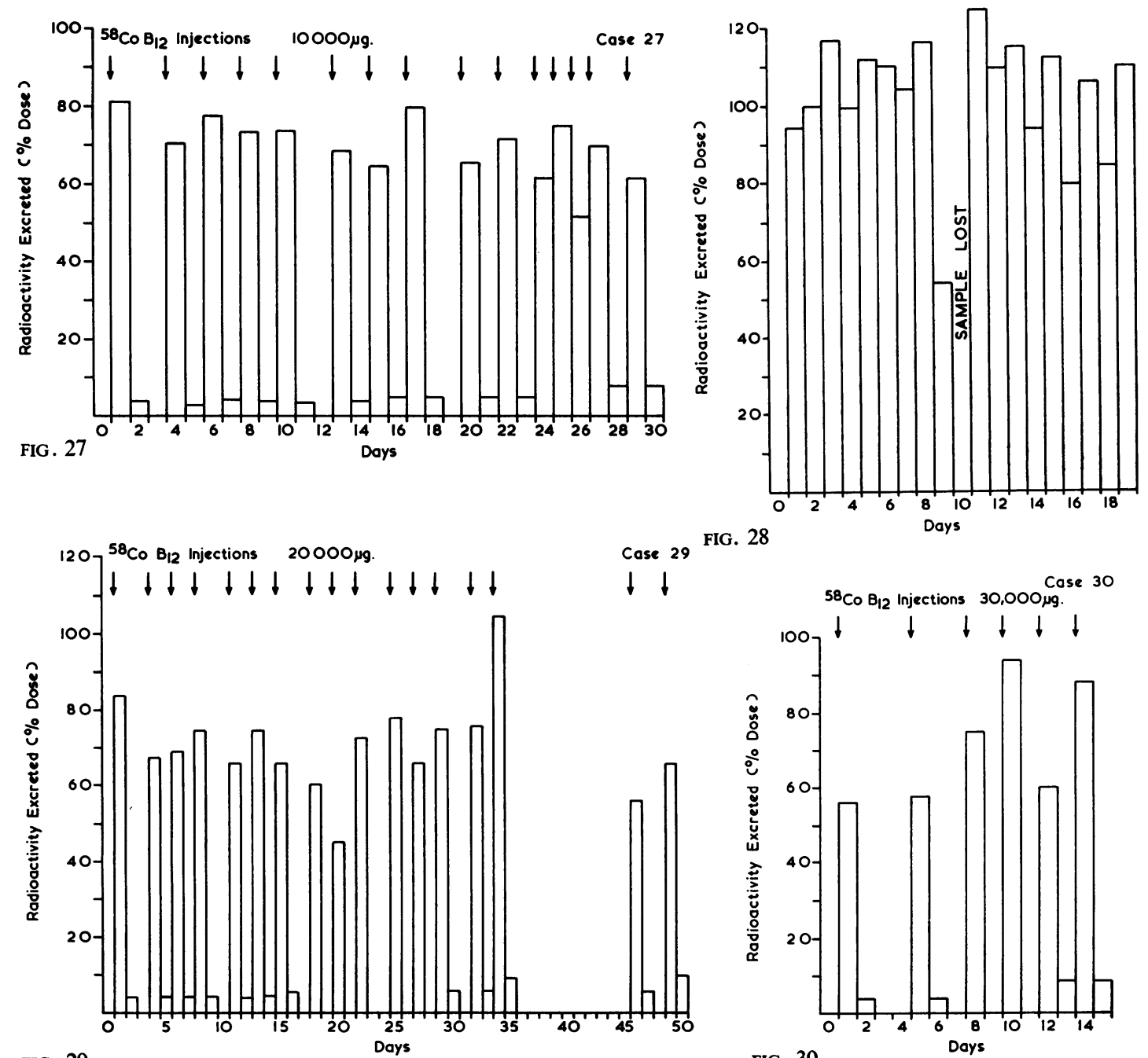

FIG. 28

${ }^{58} \mathrm{CO}_{12}$ Injections $10,000 \mathrm{\mu g}$.

Case 28

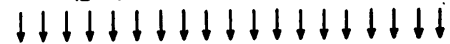

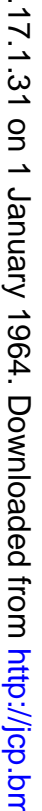

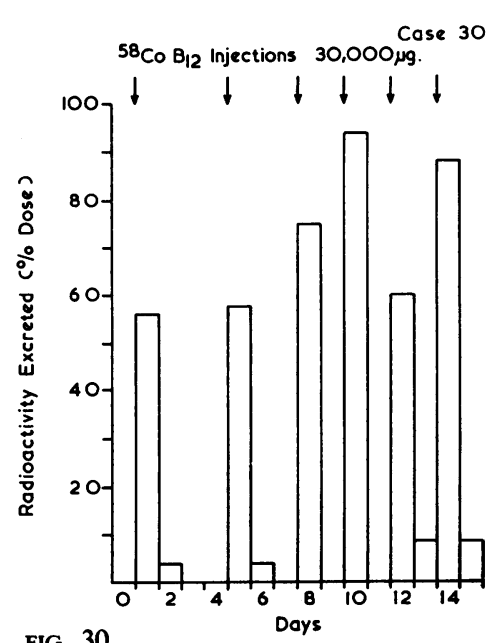

을

옥

글

N

స్ల

श्र

$\stackrel{0}{\frac{0}{D}}$

$\stackrel{\mathscr{D}}{\longrightarrow}$

꿍

$\stackrel{\text { }}{\stackrel{\mathbb{P}}{\mathbb{D}}}$

FIG. 29

FIG. 30 
TABLE II

DOSE OF ${ }^{58}$ CO VITAMIN $B_{12}$ AT EACH INJECTION AND MEAN AMOUNTS AND STANDARD DEVIATION OF RADIOACTIVITY EXCRETED FOR THE SERIES OF INJECTIONS AS PERCENTAGE OF AMOUNT OF RADIOACTIVITY IN ONE DOSE

\begin{tabular}{llll} 
Case No. & $\begin{array}{l}{ }^{58} \text { Co Vitamin } B_{12} \\
\text { Injected Dose ( } \mu g .)\end{array}$ & $\begin{array}{l}\text { Mean Radioactivity } \\
\text { Excreted }\end{array}$ \\
\cline { 3 - 5 } & $\begin{array}{l}\text { Percentage of } \\
\text { Single Dose }\end{array}$ & S.D.
\end{tabular}

\begin{tabular}{|c|c|c|c|}
\hline 1 & 54 & $13 \cdot 7$ & 6.4 \\
\hline 2 & 54 & $28 \cdot 3$ & $4 \cdot 1$ \\
\hline 3 & 54 & 9.1 & $5 \cdot 2$ \\
\hline 4 & 100 & 26.9 & 13.6 \\
\hline 5 & 100 & 49.9 & $8 \cdot 2$ \\
\hline 6 & 100 & 54.6 & $12 \cdot 2$ \\
\hline 7 & 100 & 53.6 & 6.9 \\
\hline 8 & 100 & $30 \cdot 4$ & $9 \cdot 7$ \\
\hline 9 & 100 & 42.2 & 11.0 \\
\hline 10 & 540 & $71 \cdot 7$ & 5.0 \\
\hline 11 & 540 & 70.9 & $7 \cdot 5$ \\
\hline 12 & 1,000 & $71 \cdot 7$ & 12.0 \\
\hline 13 & 1,000 & 65.8 & 18.5 \\
\hline 14 & 1,000 & 73.9 & 14.9 \\
\hline 15 & 1,000 & 52.0 & $13 \cdot 3$ \\
\hline 16 & 1,000 & 65.7 & 7.4 \\
\hline 17 & 1,000 & 66.0 & $9 \cdot 7$ \\
\hline 18 & 1,000 & $74 \cdot 8^{1}$ & 8.7 \\
\hline 19 & 1,000 & 68.9 & $17 \cdot 6$ \\
\hline 20 & 1,140 & $64 \cdot 4$ & 11.4 \\
\hline 21 & 1,140 & $68 \cdot 6$ & $14 \cdot 2$ \\
\hline 22 & 5,000 & 80.8 & 10.6 \\
\hline 23 & 5,000 & $85 \cdot 7$ & 4.8 \\
\hline 24 & 5,000 & $82 \cdot 1$ & $10 \cdot 4$ \\
\hline 25 & 5,000 & 83.9 & 6.9 \\
\hline 26 & 10,000 & $63 \cdot 7^{1}$ & $13 \cdot 6$ \\
\hline 27 & 10,000 & $74 \cdot 3^{1}$ & $8 \cdot 6$ \\
\hline 28 & 10,000 & 101.9 & 16.7 \\
\hline 29 & 20,000 & $76 \cdot 1^{1}$ & 13.9 \\
\hline 30 & 30,000 & $75.9^{1}$ & $15 \cdot 76$ \\
\hline
\end{tabular}

${ }^{1}$ Values relating to 48 -hour collections of urine. All other values refer to 24-hour collections of urine.

of ${ }^{58} \mathrm{Co}$ vitamin $\mathrm{B}_{12}$ is due to intact ${ }^{58} \mathrm{Co}$ vitamin $B_{12}$ molecules and not to free ${ }^{58} \mathrm{Co}$ or to other ${ }^{58}$ Co-containing compounds (Chow, Rosenblum, Silber, Woodbury, Yamamato. and Lang, 1951; Smith, 1952, 1953; MacLean and Bloch, 1954) and in the dose range 0 to $1,114 \mu \mathrm{g}$. it has been shown that the radioactivity in urine after parenteral infections of ${ }^{58} \mathrm{Co}$ vitamin $\mathrm{B}_{12}$ is a direct measure of the microbiologically active material regardless of the body stores of cyanocobalamin (Adams, 1961). The assumption that this is also the case with larger doses seems acceptable, particularly as the patients in this series had low serum cyanocobalamin levels and presumably trivial body stores when the study began. The actual diagnosis in each case is only of passing interest; the essential point is that all patients were deficient in vitamin $B_{12}$ before treatment.

An increase in the proportion of injected cyanocobalamin which is excreted in urine with repeated injections has been reported in vitamin $B_{12}$-deficient patients (Sokoloff, Sanneman, and Beard, 1952; Mollin and Ross, 1953), in normal subjects (Chesterman, Cuthbertson, and Pegler, 1951; Sokoloff et al.,
1952; Estrada, Lang, and Chow, 1954), and in one rat (Harte, Chow, and Barrows, 1953). In all but one of these investigations the method adopted was to measure the urinary loss by microbiological assay after a single injection of vitamin $\mathbf{B}_{\mathbf{1 2}}$, to give 'saturating' intramuscular doses ranging from $20 \mu \mathrm{g}$. daily for two weeks (Chesterman et al., 1951) to $1,000 \mu \mathrm{g}$. daily for seven days (Mollin and Ross, 1953), and then to measure the urinary loss after a further injection of vitamin $B_{12}$, the dose given being the same as that at the first injection. The conclusion that the proportion excreted increased as the body stores were augmented was based on the finding of a greater amount excreted after the second dose. The possibility that the amount excreted after each injection might vary from day to day was considered by Mollin and Ross (1953) but was not thought to constitute a significant variable. From the results shown in Figs. 1 to 30 and Table II it is clear that the amount excreted in urine by any one subject given repeated injections of the same dose of ${ }^{58} \mathrm{Co}$ vitamin $\mathrm{B}_{12}$ may vary to a considerable degree from day to day and it seems likely that this factor is more important than believed previously. It is also clear from the results that the amount excreted by different patients given the same dose of vitamin cyanocobalamin may vary considerably.

Taking all the results shown in Figs. 1 to 30 into consideration, they show no constant trend to the excretion of greater or smaller proportions of the amounts injected. In some there is an apparent trend for the excretion of greater amounts with repeated injections and in a few others the opposite appears to obtain, but from the overall picture it seems likely that these apparent trends would have disappeared had the observation periods been extended. The results also show that it is unlikely that there is any stage at which the amount of vitamin cyanocobalamin excreted in urine is maintained in a plateau-like fashion. The overlap of total amounts of ${ }^{58} \mathrm{Co}$ vitamin $\mathrm{B}_{12}$ retained in the body shown in Table $I$ is additional evidence. In calculating the total amounts of ${ }^{58} \mathrm{Co}$ vitamin $B_{12}$ retained in the body no allowance was made for intestinal loss as this is trivial and can be disregarded for practical purposes (Adams, 1963).

The extraordinary capacity of these vitamin $B_{12}$-deficient patients to retain very large amounts of ${ }^{58} \mathrm{Co}$ vitamin $\mathrm{B}_{12}$ has not been reported previously. As the amounts retained were often greatly in excess of those present in tissues, as determined by microbiological assay, it seems probable that this capacity is also enjoyed by normal subjects. If this is the case it is surprising that it has not been utilized by nature. Part of the explanation may be that the extent of the body stores is limited by the amounts which 
can be absorbed from dietary sources and that the amounts in normal tissues represent a nice balance between intake and expenditure allowing for all eventualities other than complete deprivation.

The ease with which very large amounts of vitamin $\mathrm{B}_{12}$ can be deposited and retained in tissues is of interest in relation to the treatment of patients requiring maintenance therapy with vitamin $B_{12}$, and the results appear to support the concept that it is a practical proposition to treat such patients by a series of injections at very long intervals. No contraindications to this form of therapy in the form of toxic effects were observed in any patient in this series and all, except case 28, a patient who had atrial fibrillation and gross hypertension and died of a cerebrovascular accident 10 months after treatment, have been followed up for at least three years. There are, however, good reasons why this form of therapy is unlikely to be of practical therapeutic value. In the first place the percentage of the dose of cyanocobalamin which is excreted increases as the dose is increased, the amount excreted being related not to the dose but to the logarithm of the dose, so that relatively little is gained in terms of deposition of vitamin $B_{12}$ in tissues by the use of very large doses (Adams, 1962). In the second place the duration of effect of the cyanocobalamin retained in the body, as measured by the time for which the serum vitamin $B_{12}$ level remains above the lower limit of normal (140 $\mu \mu \mathrm{g} . / \mathrm{ml}$. by the method used) in patients with pernicious anaemia, is not directly proportional to the amount in tissues but related in a linear manner to the logarithm of the retained dose, so that a very great increase in the amount retained in the body causes only a slight increase in the duration of effect (Adams, 1962). For example, with an injection of $100 \mu \mathrm{g}$. the mean calculated amount retained is $67 \mu \mathrm{g}$. and the mean calculated duration of effect of this retained dose as previously defined is 31 days; with an injection of $1,000 \mu \mathrm{g}$. the mean calculated retained dose is $372 \mu \mathrm{g}$. and the mean calculated duration of effect is only increased to 43 days; with an injection of $10,000 \mu \mathrm{g}$. the mean calculated retained dose is $808 \mu \mathrm{g}$. and the mean calculated duration of effect only 49 days. For these reasons, and the obvious financial implications, it is doubtful if massive parenteral injections of cyanocobalamin have anything to commend their use in clinical practice, at least in the maintenance therapy of patients with vitamin $B_{12}$ deficiency states.

It is generally held that the urinary excretion of injected cyanocobalamin is complete within 24 hours after injection (Smith, 1960) and with doses of 40 to $80 \mu \mathrm{g}$. there is good evidence that urinary excretion is virtually complete within eight hours (Mollin and Ross, 1953). In general the results in this series confirm these findings, although in one patient

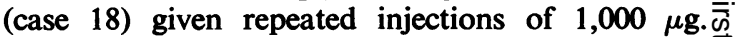
significant amounts of radioactivity were excretedo in the period 24 to 48 hours after injection. No듬 reason for this was found and it is possible that this is a biological abnormality. It is also possible that $\mathbb{\nabla}$ it was not pure cyanocobalamin but contained $a_{0}$ proportion of the hydroxo form which may continue ${ }^{\text {s }}$ to be excreted for up to 72 hours after injection. $\vec{\circ}$ As this pattern of excretion was not seen in any $\overrightarrow{\vec{H}}$ other patient studied at this time and given the same dose and as the total amounts excreted were more응 in keeping with those excreted after an injection of cyanocobalamin than after an injection of hydroxo- -7 cobalamin, the latter possibility seems less likely. $\vec{\omega}$ With injections of $5,000 \mu \mathrm{g}$. or more the results show that excretion can be expected to continue ins the 24 to 48 hours after injection but the amountsexcreted are relatively small. It is clear that the amounts excreted in this late period were not? large enough to have obscured any trend to the excretion of larger or smaller proportions of re- $\vec{\varphi}$ peated injections of cyanocobalamin.

I am grateful to Dr. J. A. W. McCluskie for advice andర criticism and for access to patients; to Professor E. J. Wayne for facilities in his department; to the Regional Physics Department, Western Regional Hospital Board, for supplies of ${ }^{58} \mathrm{Co}$ vitamin $B_{12}$, and to the nursing staffo of wards C. 9 and 10 and the patients for their co-Q operation.

\section{REFERENCES}

Adams, J. F. (1961). J. clin. Path., 14, 351.

(1963). Scot. med. J. 8, 118.

(1962). In Vitamin $B_{12}$ und Intrinsic Faktor, 2nd European Symposium, edited by H. C. Heinrich, p. 628. Enke, Stuttgart - and Seaton, D. A. (1961). J. Lab. clin. Med., 58, 67.

Chesterman, D. C., Cuthbertson, W. F. J., and Pegler, H. F. (1951)이 Biochem. J., 48, 51.

Chow, B. F., Rosenblum, C., Silber, R. H., Woodbury, D. T. Yamamato, R., and Lang, C. A. (1951). Proc. Soc.exp. Biol O (N.Y.), 76, 393.

Estrada, S. C., Lang, C. A., and Chow, B. F. (1954). J. Lab. clin. Med., 43, 406.

Girdwood, R. H. (1960). Scot. med. J., 5, 10.

Harte, R. A., Chow, B. F., and Barrows, L. (1953). J. Nutr., 49, 669

Hutner, S. H., Bach, M. K., and Ross, G. I. M. (1956). J. Protozool., 3, 101.

Kay, A. W. (1953). Brit. med. J., 2, 77.

Killander, A. (1957). Acta Soc. Med., upsalien., 62, 39.

(1958). Ibid., 63, 14.

MacLean, L. D., and Bloch, H. S. (1954). Proc. Soc. exp. Biol. (N. Y.) N 87, 171.

Mollin, D. L., and Ross, G. I. M. (1953). Brit. med. J., 2, 640.

Ross, G. I. M., Hutner, S. H., and Bach, M. K. (1957). In Vitamin $B_{12}$ und Intrinsic Faktor, 1st European Symposium, edited by H. C. Heinrich, p. 305. Enke, Stuttgart.

Schilling, R. F. (1953). J. Lab. clin. Med., 42, 860.

Shinton, N. K. (1959). Clin. Sci., 18, 389.

Smith, E. L. (1952). Brit. med. Bull., 8, 203.

(1953). In Radioisotope Techniques. Proceedings of the Isotope Technique Conference, Oxford, July 1951, Vol. 1, p. 281त H.M.S.O., London.

Sokoloff, M. F., Sanneman, E. H. Jr., and Beard, M. F. (1952). Blood 7, 243. 